\title{
RAPD fingerprinting of the ornamental fish Badis badis (Hamilton 1822) and Dario dario (Kullander and Britz 2002) (Perciformes, Badidae) from West Bengal, India
}

\author{
Manoj P. Brahmane, Krishna Mitra and Sudhanshu S. Mishra \\ Central Inland Fisheries Research Institute, Barrackpore, Kolkata, India.
}

\begin{abstract}
We used random amplification of polymorphic DNA (RAPD) to generate species-specific diagnostic fragment patterns for the molecular identification of the ornamental aquarium fish species Badis badis and Dario dario. Seven arbitrary oligodecamer primers produced a total of 116 bands of which $98.23 \%$ were polymorphic. The size of the amplified products was in the range $340 \mathrm{bp}$ to $2170 \mathrm{bp}$. Intraspecies genetic similarity was $0.879 \pm 0.023$ for $B$. badis and $0.840 \pm 0.014$ for $D$. dario while interspecies genetic similarity was $0.602 \pm 0.017$, with cluster analysis displaying separate taxonomic and evolutionary status for these fish. The results show that RAPD was useful for the molecular identification of aquarium fish species, with morphological traits also being important.
\end{abstract}

Key words: Badis badis, Dario dario, diagnostic markers, RAPD molecular identification, West Bengal.

Received: July 11, 2007; Accepted: November 26, 2007.

India is endowed with a vast fish biological resource representing more than $10 \%$ of world fish diversity (Das and Pandey, 1998). However, most indigenous aquarium fish have not been genetically characterized and documented and are being indiscriminately caught from their natural environments leading to their depletion and probable extinction. Taxonomic methods of fish identification and characterization are primarily based on morphological characters which may sometimes be insufficient to identify a species, particularly in the early stages of development when only a few morphological characters are observable (Ayoma et al., 2000). The ornamental freshwater fish Badis badis (Hamilton, 1822) and Dario dario (Kullander and Britz 2002) (Actinopterygii, Perciformes, Badidae) can be distinguished morphologically, with $B$. badis being distributed throughout Asia in Bangladesh, Bhutan, India and Nepal, while $D$. dario is found in the North Eastern region of India in Assam, Bihar and West Bengal. These species have undergone a series of revisions in taxonomic status at genus and species level. Hamilton (1822) placed these fish in the genus Labrus and named them Labrus badis and Labrus dario respectively. Much later, Talwar and Jhingran (1991) considered both $B$. badis and $D$. dario to be $B$. badis, while Tomey (1999) considered $D$. dario to be a subspecies of $B$. badis ( $B$. badis bengalensis) but, more recently, Kullander

Send correspondence to Manoj P. Brahmane. Central Inland Fisheries Research Institute (ICAR), 700120 Barrackpore, Kolkata, India. E-mail: mbrahmane@yahoo.com. and Britz (2002) revised the family Badidae and placed Badis badis bengalensis in the new genus Dario.

The objective of the study described in this paper was to use random amplified polymorphic DNA (RAPD) markers to develop genetic baseline data for these fish and also provide genetic data to clarify the taxonomic status of $B$. badis and $D$. dario which have undergone recent changes in nomenclature and systematic position.

Specimens of B. badis and D. dario were collected from sites in the Nadia district $\left(22^{\circ} 56^{\prime} 11.36^{\prime \prime} \mathrm{N}\right.$,

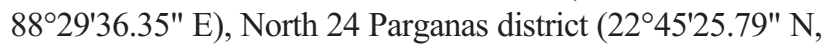
$\left.88^{\circ} 25^{\prime} 4.59^{\prime \prime} \mathrm{E}\right)$ and Cooch Bihar region $\left(26^{\circ} 18^{\prime} 18.48^{\prime \prime} \mathrm{N}\right.$, $89^{\circ} 26^{\prime} 51.71 " \mathrm{l}$ ) of the Indian state of West Bengal. A total of 20 specimens were collected for each species and preserved in $90 \%$ ethanol. For each fish, Genomic DNA was extracted from muscle following the protocol of Sambrook and Russel (2001) with minor modifications. The polymerase chain reaction (PCR) was carried out in a $25 \mu \mathrm{L}$ reaction mixture consisting of $100 \mathrm{ng}$ DNA, $100 \mathrm{pM}$ of decamer primer, $10 \mathrm{mM}$ dNTP mixture (Dynazyme), 10X PCR buffer (Dynazyme), $1.5 \mathrm{mM} \mathrm{MgCl}_{2}$ and 0.05 units of Taq polymerase (Dynazyme). Reactions were carried out using a GeneAmp PCR system 2400 (Applied Biosystems) programmed for one step of $4 \mathrm{~min}$ at $94^{\circ} \mathrm{C}, 40$ cycles of $1 \mathrm{~min}$ at $94{ }^{\circ} \mathrm{C}, 1 \mathrm{~min}$ at $34^{\circ} \mathrm{C}$ and $2 \mathrm{~min}$ at $72^{\circ} \mathrm{C}$, followed by a final extension step of $10 \mathrm{~min}$ at $72^{\circ} \mathrm{C}$. All primers used were 10 base oligomers obtained from Operon Technologies (Alameda, USA). Twenty oligodecamer primers from Kit 
A and Kit B were initially screened for amplification of genomic DNA by PCR and seven oligodecamer primers were selected depending on repeatability and reproducibility of amplified fragment patterns. The RAPD products were analyzed by electrophoresis in $1.6 \%(\mathrm{w} / \mathrm{v})$ agarose gels run for $2 \mathrm{~h}$ using $0.5 \mathrm{X}$ TBE buffer $(0.89 \mathrm{M}$ Tris-borate, $\mathrm{pH}$ 8.3, 0.02 M EDTA, for 10X). Gels were stained with $0.5 \mu \mathrm{g} \mathrm{mL}^{-1}$ ethidium bromide and photographed under UV light using a BioRad gel documentation system. The DNA fragment sizes were estimated by comparison with a standard 100 bp ladder (Sigma) using Biol-D software. The RAPD fragments were scored for either the presence (1) or absence (0) of a homologous amplification product. Genetic similarity was calculated and the unweighted pair group method with averages (UPGMA) was used to construct a dendrogram (Nei, 1978) of the scored data using PopGene-v 1.31(Yeh, 1999).

Seven primers (OPA-03, OPA-08, OPB-08, OPB-12, OPB-14, OPB-17, and OPB-18) produced 116 fragments with $98.23 \%$ polymorphism (Figure 1), of which 47 fragments were generated from B. badis and 69 fragments from $D$. dario. Numbers and sizes of scorable fragments varied from 1 to 12 , with a size range of $340 \mathrm{bp}$ to $2170 \mathrm{bp}$ (Table 1). The two species could be unambiguously identified using 26 RAPD markers, of which 9 occurred in $B$. badis and 17 in $D$. dario. In $B$. badis primer OPA-8 produced one diagnostic band, OPA-3 two bands and OPB-14 and OPB-18 three bands each, while in $D$. dario primers
OPB-17 and OPB-18 produced one diagnostic band each, OPA- 8 three bands, OPB-14 four bands and OPB- 8 five bands (Table 1). The highest number of fragments for $B$. badis were the 9 produced by primer OPB- 08 , while for $D$. dario the highest number was the 12 produced by primer OPA-03. Genetic similarity ranged from 0.836 to 0.906 for $B$. badis and 0.819 to 0.857 for $D$. dario, while the average intraspecies genetic similarity was $0.879 \pm 0.023$ for $B$. badis and $0.840 \pm 0.014$ for $D$. dario. Interspecies genetic similarity between the two species was $0.602 \pm 0.017$ and the UPGMA dendrogram (Figure 2) grouped the two species into separate clusters emphasizing the distinct species status of $B$. badis and $D$. dario.

Callejas and Ochando (2001) used 10 primers and observed 48 species-specific RAPD diagnostic bands which were able to unambiguously differentiate eight Barbus species from the Iberian Peninsula, with three markers in $B$. guiraonis, four in B. bocagei, B. microcephalus and $B$. scalateri, five in $B$. graellsii, seven in B. comiza, eight in $B$. hassi and thirteen in B. meridionalis. Dinesh et al., (1993) used 9-mer primers to generate DNA fingerprints for freshwater fish belonging to the families Anabantidae, Belontidae, Chararidae, Cyprinidae and Salmonidae. Ruzainah et al. (2003) used five primers and RAPD analysis to diagnostically identify the eel-loaches Pangio filinaris and Pangio piperata, the genetic similarity between these two species $(0.609 \pm 0.22)$ being comparable to the average genetic similarity $(0.602 \pm 0.17)$ estimated by

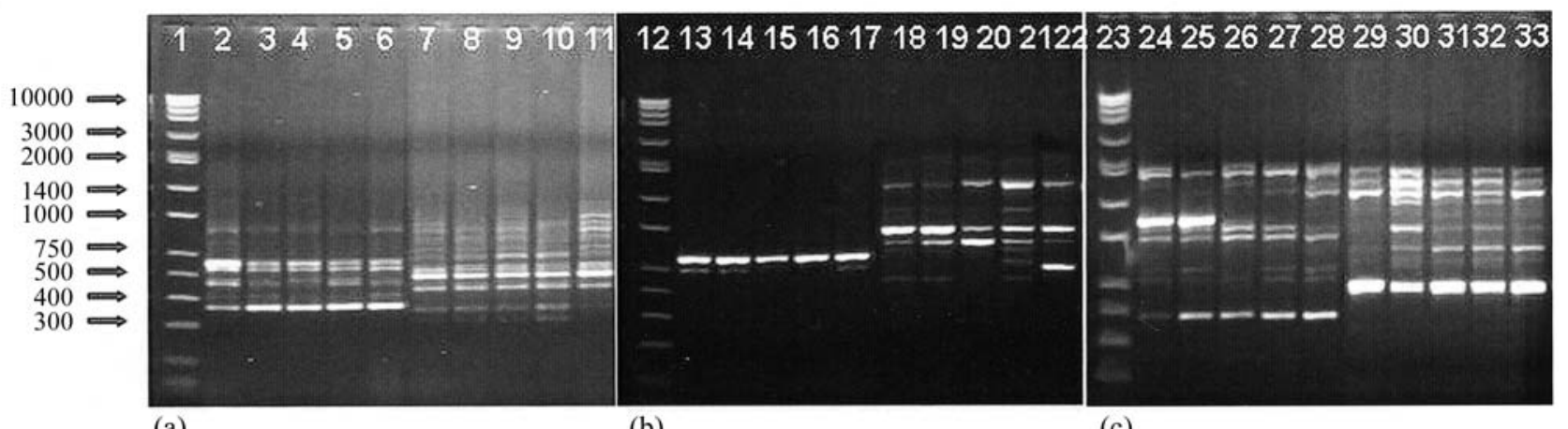

(a)

(b)

(c)

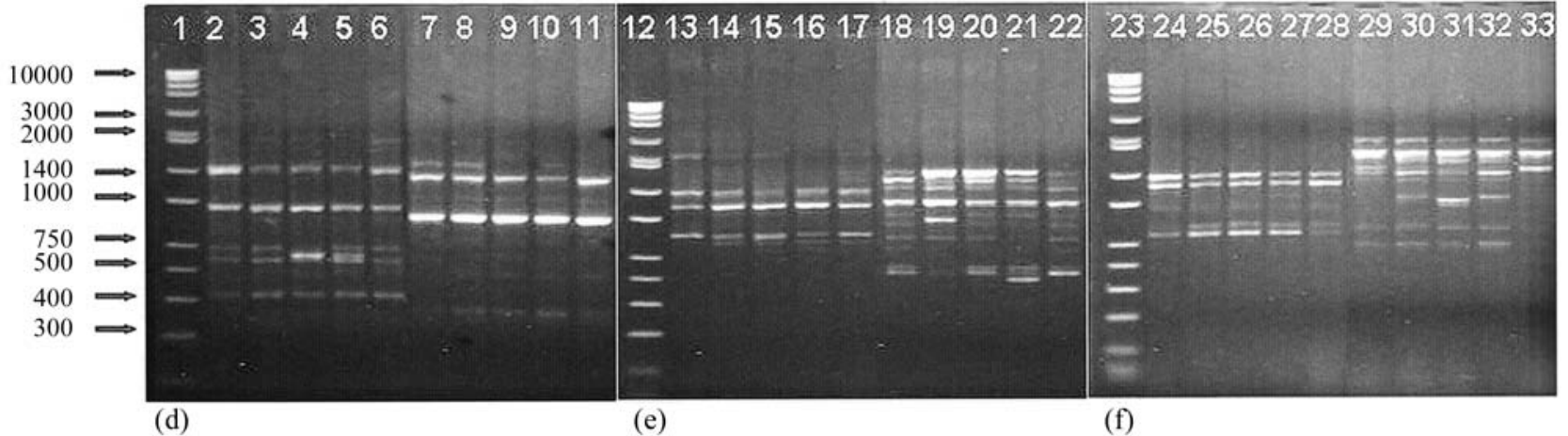

Figure 1 - The RAPD fragment patterns of Badis badis (lanes 2-6, 13-17, 24-28) and Dario dario (lanes 7-11, 18-22, 29-33) using primer (a) OPA-03, (b) OPA-08 (c) OPB-08 (d) OPB-12 (e) OPB-14 (f) OPB-18. Lane 1, 12, 23 represent wide range DNA molecular weight ladder. 
Table 1 - Number and size of fragments amplified by different RAPD primers used and molecular weight of diagnostic markers for Badis badis and Dario dario.

\begin{tabular}{|c|c|c|c|c|c|c|c|c|}
\hline \multirow[t]{3}{*}{ Primer } & \multirow[t]{3}{*}{ Sequence ( $5^{\prime}$ to $\left.3^{\prime}\right)$} & \multirow{3}{*}{$\begin{array}{c}\mathrm{G}+\mathrm{C} \\
\text { content } \\
(\%)\end{array}$} & \multicolumn{2}{|c|}{ Number of fragments } & \multicolumn{4}{|c|}{ Size range and diagnostic fragments (bp) } \\
\hline & & & \multirow[t]{2}{*}{ Badis badis } & \multirow[t]{2}{*}{ Dario dario } & \multicolumn{2}{|c|}{ Badis badis } & \multicolumn{2}{|c|}{ Dario dario } \\
\hline & & & & & Size range & Diag. frag. & Size range & Diag. frag \\
\hline OPA-3 & AGTCAGCCAC & 60 & $4-6$ & $8-12$ & $930-370$ & $\begin{array}{l}530 \\
370\end{array}$ & $990-340$ & $\begin{array}{l}950 \\
780 \\
460\end{array}$ \\
\hline OPA-8 & GTGACGTAGG & 60 & $1-2$ & $3-9$ & $820-720$ & 820 & $2070-580$ & $\begin{array}{r}1470 \\
970 \\
920\end{array}$ \\
\hline OPB-8 & GTCCACACGG & 70 & $4-9$ & $6-10$ & $1690-420$ & - & $1500-670$ & $\begin{array}{r}1490 \\
1450 \\
930 \\
860 \\
670\end{array}$ \\
\hline OPB-12 & CCTTGACGCA & 60 & $4-6$ & $3-4$ & $1500-410$ & - & $1420-870$ & - \\
\hline OPB-14 & TCCGCTCTGG & 70 & $4-7$ & $6-10$ & $2130-860$ & $\begin{array}{r}1390 \\
1150 \\
920\end{array}$ & $1500-480$ & $\begin{array}{l}1500 \\
1480 \\
1440 \\
1230\end{array}$ \\
\hline OPB-17 & AGGGAACGAG & 60 & $3-6$ & $3-4$ & $1500-680$ & - & $1460-640$ & 930 \\
\hline OPB-18 & CCACAGCAGT & 60 & $3-4$ & $6-8$ & $1400-850$ & $\begin{array}{r}1400 \\
1240 \\
820\end{array}$ & $2000-750$ & 1500 \\
\hline
\end{tabular}

Diag. frag.: diagnostic fragments

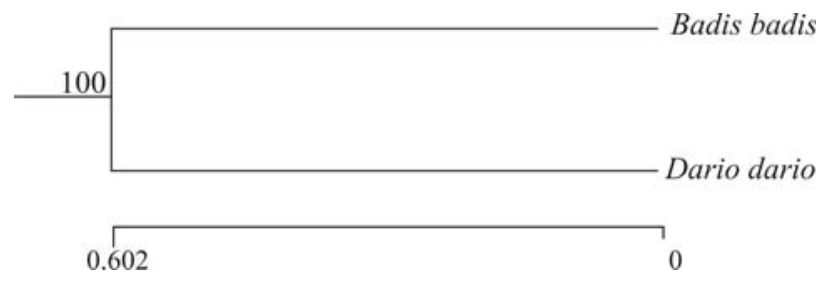

Figure 2 - UPGMA dendrogram showing genetic identity based distinct separation of Badis badis and Dario dario.

us for B. badis and D. dario. Brahmane et al., (2006) used RAPD to delineate populations of commercially important anadromous Tenualosa ilisha populations from rivers draining into the Bay of Bengal and Arabian Sea.

Our RAPD study confirms the taxonomic position of two species of commercially important ornamental fish found in India. We developed a protocol for the application of RAPD-PCR and produced baseline molecular data for $B$. badis and $D$. dario. Though RAPD produced several diagnostic markers for identification of $B$. badis and $D$. dario further development of a sequence characterized amplified region would be more useful. Due to their economic value in terms of the aquarium fish trade, identification of unique markers for species identification is essential in aquaculture programs, decreasing harvesting pressure on the naturally occurring species and leading to accurate pairing in breeding programs for commercial activity and for genetic monitoring of cultured populations for acceptable levels of genetic diversity. This RAPD methodology can also be applied to other commercially important ornamental fish species found in India, to create molecular documentation of fish species and genetic assessment of indigenous fish resources.

\section{Acknowledgments}

The authors thank Dr. K.K. Vass, Director CIFRI, Barrackpore, Dr. D. Nath and Dr. M.K. Das for providing facilities and encouragement to undertake this work. The technical assistance of D. Biswas and Mr. Rabi-ul Sheik is duly acknowledged.

\section{References}

Ayoma J, Watanbe S, Nishida M and Tsukamato K (2000) Discrimination of catadroumous eels of genus Anguilla using polymerase chain reaction restriction fragment length polymorphism analysis of the mitochondrial DNA $16 \mathrm{~S}$ ribosomal RNA domain. Trans Am Fish Soc 129:873-878.

Brahmane MP, Das MK, Sinha MR, Sugunan VV, Mukherjee A, Singh SN, Prakash S, Maurye P and Hajra A (2006) Use of RAPD fingerprinting for delineating populations of hilsa shad Tenualosa ilisha (Hamilton 1822). Genet Mol Res 31:643-652.

Callejas C and Ochando MD (2001) Molecular identification (RAPD) of the eight species of the genus Barbus (Cyprinidae) in the Iberian Peninsula. J Fish Biol 59:1589-1599.

Das P and Pandey AK (1998) Current status of fish germplasm resource of India and strategies for conservation of endan- 
gered species. In: Ponniah AG and Das P (eds) Fish Genetics and Biodiversity Conservation. Nature Conservators, Muzzaffarnagar, pp 253-273.

Dinesh KR, Lim TM, Chan WK and Phang VPE (1993) RAPD analysis: An efficient method of DNA fingerprinting in fishes. Zool Sci 10:849-854.

Hamilton F (1822) An account of the fishes found in the river Ganges and its branches. Archibald Constable and Company, Edinburgh, 405 pp.

Kullander SO and Britz R (2002) Revision of the family Badidae (Teleostei, Perciformes), with description of a new genus and ten new species. Ichthyol Explor Freshw 13:295-372.

Nei M (1978) Estimation of average heterozygosity and genetic distances from small number of individuals. Genetics 89:583-590.

Ruzainah A, Azizah MNS, Patimah I and Amiruddin A (2003) RAPD fingerprinting of the eel-loaches Pangio filinaris and
Pangio piperata: Preliminary evaluation. Aquacult Res 34:959-965.

Sambrook J and Russell DW (2001) Molecular Cloning: A Laboratory Manual. 2nd ed. Cold Spring Harbor Laboratory, New York.

Talwar PK and Jhingran AG (1991) Inland Fishes of India and adjacent countries. Oxford and IBH, New Delhi, 1158 pp.

Tomey WA (1999) Een nieuwe dwergform van Badis badis hier benoemd als ondersoort B. b. bengalensis. n. ssp. Het Aquarium 62:24-27.

\section{Internet Resources}

Yeh FC (1999) PopGene, v.1.31. http://www.ualberta.ca/ fyeh/. Associate Editor: Louis Bernard Klaczko

License information: This is an open-access article distributed under the terms of the Creative Commons Attribution License, which permits unrestricted use, distribution, and reproduction in any medium, provided the original work is properly cited. 